\title{
PERSPECTIVES
}

\section{A Window of Opportunity for the Transformation of National Mental Health Policy in Turkey Following Two Major Earthquakes}

\author{
Kerim Munir, MD, MPH, DSc, Tuncay Ergene, PhD, Verda Tunaligil, MD, MPH, and Nese Erol, PhD
}

\begin{abstract}
Striking at the nation's highly populated industrial heartlands, two massive earthquakes in 1999 killed over 25,000 people in Turkey. The economic cost and the humanitarian magnitude of the disaster were unprecedented in the country's history. The crisis also underscored a major flaw in the organization of mental health services in the provinces that were left out of the 1961 reforms that aimed to make basic health services available nationwide. In describing the chronology of the earthquakes and the ensuing national and international response, this article explains how the public and governmental experience of the earthquakes has created a window of opportunity, and perhaps the political will, for significant reform. There is an urgent need to integrate mental health and general health services, and to strengthen mental health services in the country's 81 disparate provinces. As Turkey continues her rapid transformation in terms of greater urbanization, higher levels of public education, and economic and constitutional reforms associated with its projected entry into the European Union, there have also been growing demands for better, and more equitably distributed, health care. A legacy of the earthquakes is that they exposed the need for Turkey to create a coherent, clearly articulated national mental health policy. (HARv ReV Psychiatry 2004;12:238-251.)
\end{abstract}

Keywords: emergency preparedness, mental health policy, natural disasters

From the Department of Psychiatry, Harvard Medical School (Dr. Munir); Department of Psychiatry (Dr. Munir) and Division of General Pediatrics (Drs. Munir and Tunaligil), Children's Hospital, Boston, MA; Department of Psychological Counseling and Guidance, Hacettepe University, Ankara, Turkey (Dr. Ergene); Department of Child Psychiatry, Ankara University School of Medicine, Ankara, Turkey (Dr. Erol).

Supported, in part, by the Recovery Plan for Turkish Children (UNICEF) (KM, TE), the Marmara Earthquake Emergency Recovery Program National Mental Health Policy Project (Ministry of Health, Turkey) (KM, TE, NE), and the National Institutes of Health/Fogarty International Center grant no. D43 TW05807 (United States) (KM, TE, VT, NE).

Original manuscript received 16 January 2004; revised manuscript received 24 May 2004, accepted for publication 4 June 2004.
On August 17 and November 12, 1999, two massive earthquakes struck the northwest of Turkey, killing over 25,000 people. With the exception of the devastating Erzincan earthquake in 1939-when more than 40,000 people perished - the country had never before faced a disaster that so shook its foundations. With tens of thousands of people injured and hundreds of thousands displaced, it was clear

Reprint requests: Kerim Munir, MD, MPH, DSc, Division of General Pediatrics, Fegan-10, Children's Hospital, 300 Longwood Ave., Boston, MA 02115. Email: kerim.munir@childrens.harvard.edu

(c) 2004 President and Fellows of Harvard College

DOI: $10.1080 / 10673220490509615$ 
that the impact of the disaster would be felt over for years, even decades. The economic costs and humanitarian consequences of the disaster were unprecedented in the country's history. The crisis also underscored a major flaw in the organization of the mental health services in the provinces that were left out of the 1961 reforms aimed at making basic health services available nationwide.

At the time of the earthquakes, half of the Turkish population of 65 million was under 25 years of age. The high birth rate, rapid urbanization, and rising income and education levels had fueled demand for better quality health services. ${ }^{1}$ Although the government had allocated more funding for public services, the investment in health care, in generaland in mental health services, in particular-had been inadequate to cope with the increased demands. Plans for the development of a national mental health policy initiative emphasizing the equitable distribution of care had been envisioned since the 1980s. The goals of that initiative included the establishment of basic mental health services within the nation's primary health care grid; the integration of mental health care with the rest of health care; and the introduction of community mental health services in the provinces. The initiative also foresaw linkages and synergies among allied sectors, and coordination among allied disciplines. For example, with regard to education, the initiative envisioned the need for child-care, preschool, maternal, and child-support services targeting at-risk youth and families; for stronger counseling and guidance services in schools; and for referral networks involving provincial counseling and guidance centers. At the core of the policy initiative remained the need for the development of decentralized and locally acceptable, but cost-effective, services. The implementation of evidence-based practice models and professional standards, development of a national medical school curriculum (following upon the recent expansion of medical schools in the provinces), and reduction of the stigma associated with the use of mental health services also remained important goals. In this respect, the collaboration between the Turkish and World Psychiatric Associations, as well as that between the Turkish Child and Adolescent Psychiatry Association and its European partners, helped to set the stage for a vision of the future.

The national Mental Health Department, administered under the General Directorate of Primary Health Care in the Ministry of Health $(\mathrm{MoH})$, was founded in 1983. The department had only rarely been led by mental health specialists, the preference being for public health specialists or graduates of high schools that gave certificates in health administration. The department therefore depended on episodic utilization of "national expert teams" and international consultations. The cooperation among various directorates in any given ministry, as well as the coordination across ministries, had been inadequate because of competing interests within coalition parties or because of bureaucratic barriers. Integration of services was nevertheless possible-under a special secretariat reporting to the Prime Ministry—on projects requiring intersectoral collaboration or greater transparency.

In Turkey, each of the 81 provinces is headed by an appointed governor who reports to a nationally elected government, and each has a department of health within which there is also a mental health department. Many of these locally administered mental health units exist in name only, however, since many of the positions have remained unfilled. Of the 784 staff psychiatrists (excluding trainees), 359 were employed in the $\mathrm{MoH}$ hospitals, with the overwhelming number of these specialists based in the major cities of Ankara, İstanbul, and İzmir. ${ }^{2}$ The national ratio for specialists in psychiatry remained around 1 per 100,000 population, ${ }^{3}$ increasing to 1 per 50,000 in metropolitan İstanbul (Munir K, unpublished data). By way of contrast, the United States, according to the president of the American Psychiatric Association, has over 16 psychiatrists per 100,000 population. ${ }^{4}$

At the time of the earthquakes, there were about 50 child psychiatrists in the country. ${ }^{5}$ With a third of the population being 15 years of age and under, the ratio of child psychiatrists remained around 1 per 500,000 for children and adolescents age 15 and under. Of the total number of child psychiatrists, $80 \%$ were based in the three major citieswhere 13 of the country's 19 total child psychiatry units were located-and worked mostly in university settings. The remaining 6 units were affiliated with universities in the smaller cities of Adana, Antalya, Bursa, Gaziantep, Kocaeli, and Trabzon. In Ankara, there were also two adolescent units located within adult psychiatry clinics, and in Istanbul there was an adolescent unit in the Institute for Child Health. Beyond these settings, there was a handful of selfemployed child psychiatrists - three-in the entire country.

Historically, a strength of the health care system in Turkey, at least since the passage of the basic health law in 1961, has been the development of a primary health care grid of about 5,800 centers, administered under MoH's Directorate of Primary Health Care and the provincial directorates of health. MoH also has jurisdiction over the development and dissemination of preventive services; integration of mental health and primary care; community education and identification of risk-behavior groups; creation of counseling and guidance units; creation of psychiatric units in state hospitals; development of rehabilitation facilities; public education through the mass media; and data collection and research. Despite such a well-developed institutional framework, however, there were no functional basic mental health services available at the primary health care level. This lack of services proved to be especially unfortunate after the earthquakes. 
In the primary health care centers in the provinces, the general practitioner staff has typically received, beginning in medical school, widely varying (but generally poor) training in mental health. Subsequent, on-site training in mental health is irregular because there is typically no ongoing psychiatric staff available; the only additional training in mental health is associated with brief training sessions organized by the $\mathrm{MoH}$ or national nongovernmental organizations (NGOs) through the provincial primary care centers. By way of contrast, many of the psychiatric specialists in Turkey have participated in mandatory service in the provinces (as part of a national requirement for all graduating physicians, a practice only recently discontinued) and therefore have gained considerable knowledge about provincial mental health problems and services. Ironically, however, these psychiatric specialists remain concentrated in large cities, where there is a strong demand for their services. This lopsided distribution of psychiatric services is, moreover, likely to continue; because of the limited salaries in both the university and public sectors (even in the cities), psychiatrists will become increasingly dependent on the opportunities that cities provide for supplementing that income by maintaining private psychiatry practices on the side.

In the decade preceding the earthquakes, epidemiological studies had shown that many families with mentally ill family members preferred to travel considerable distances to seek help from specialists located in the main cities. Kilic and colleagues ${ }^{6}$ found that in seven psychiatric centers in Ankara, the referral pattern for mental health services was different from that for general medical care; patients and families seeking mental health services would bypass primary care centers and seek help directly from psychiatric centers and specialists. The findings suggest that patients and their families recognized, and acted to surmount, the void in mental health services in primary care centers. Of 582 patients seen in these psychiatric centers during a calendar month, only $4 \%$ had been referred by their primary practitioners; $42 \%$ had been referred by hospital doctors; and $53 \%$ came directly. One percent of all the patients had consulted religious healers before going to the psychiatric centers. Despite the relative sparseness of psychiatric services in Turkey, the median time differential between requesting and receiving psychiatric services was only one week. By contrast, the delay was significantly longer when patients presented with somatic symptoms or consulted hospitalbased nonpsychiatric specialists. The limited recognition of mental health problems in primary care and the inappropriate delays in hospital-based practice suggest that physicians practicing in those settings also need better training in how to recognize and manage basic mental disorders.

The deficiencies of the mental health services in Turkey became all too apparent in the wake of the 1999 earth- quakes. It is these deficiencies, the national and international response to the devastation of the earthquakes themselves, and the subsequent reorientation of Turkey's mental health policy that we will be discussing in the remainder of this article. First, we describe the immediate aftermath and the intensity of the physical and psychological devastation caused by the two earthquakes. Second, we describe the psychosocial and mental health activities targeting children, mothers, and families under the Recovery Plan for Turkish Children funded by the United Nations Children's Fund (UNICEF) in Ankara, Turkey. Finally, we describe the activities of the Marmara Earthquake Emergency Reconstruction (MEER) mental health project, undertaken by MoH and sponsored by the World Bank, to develop a national mental health policy and to establish effective mental health services across the country. A key goal has been to use the earthquake tragedy as a powerful, albeit unfortunate, catalyst for the further development of a national mental health policy. In this context, Turkey's efforts to build its research capacity have also received a much-needed boost-in particular, through new programs funded by the United States' National Institutes of Health and Fogarty International Center. Such programs not only sustain and build interest in research, but promote collaboration among different sectors. It is also hoped that by strengthening the research conducted at the major universities, those universities will become, in turn, flagships for the development of other mental health research centers throughout the country.

\section{MARMARA EARTHQUAKE}

In less than a minute, at 3:02 a.m. on August 17, 1999, the lives of the Turkish people changed forever. A major earthquake measuring 7.4 on the Richter scale (RS) struck the nation's Marmara region, which includes İstanbul and the heavily populated industrial heartland. The estimated loss of life under the massive destruction of buildings far exceeded the official toll of 18,000; many, many people were not recovered. ${ }^{7}$ An additional 45,000 people were injured, and more than half a million were in immediate need of shelter. One percent of the overall Turkish population was directly affected by this earthquake. The province and port city of Kocaeli (also known as İzmit), the naval dockyards at Gölcük, the provinces of Yalova and Sakarya (with its ancient capital Adapazarı), and the mountainous province of Bolu (on the pass between İstanbul and Ankara) bore the brunt of the sustained tremors. Nearly $80 \%$ of Gölcük's buildings were damaged or destroyed-not just by the powerful initial tremor, but also by a six-foot drop in the seabed that triggered a tidal wave that engulfed part of the coastal town. The adjacent cities of Bursa and Eskişehir, as well as the districts of Avcilar and Bağcılar in the İstanbul province, 
were also affected. The proportionate impact in the United States would be analogous to 100,000 lives lost, 225,000 injured, and 2.25 million in need of immediate shelter. The earthquake's economic impact was equally devastating: onethird of Turkey's industrial infrastructure came to a standstill because of disruptions to the road and railway transportation systems, water and sewage lines, electrical grid, and oil-refining capacity.

\section{DÜZCE EARTHQUAKE}

Three months later, on November 12, 1999, the Kandilli Observatory in Istanbul measured a second powerful earthquake in the same general region as the first; measuring 7.2 RS, its epicenter lay roughly 50 miles (just under 100 kilometers) immediately east of the first in the provinces of Düzce and Bolu (Figure 1). An additional 850 persons were killed, 4,500 injured, and 250,000 made homeless. Further injuries were minimized for a variety of reasons. Fearing the effects of aftershocks, many inhabitants had left their homes and were living in tents. Moreover, unlike the Marmara earthquake, which had struck in the middle of the night, this second, Düzce earthquake struck at 7:00 p.m., when most people were awake. Also important was that, due to the previous, nearby Marmara earthquake, the emergencyresponse teams were already close at hand, as were various NGOs that had mobilized in the region. Even so, this second earthquake proved to have an especially distressing impact on the residents of the socioeconomically depressed town of Kaynaşlı in the Düzce province. (A similar situation was noted by Goenjian and colleagues ${ }^{8}$ with respect to the Yerevan earthquakes and described conceptually by Yehuda and colleagues ${ }^{9}$ among Holocaust victims.) Making matters even worse was that the approaching winter proved to be especially harsh, isolating survivors and restricting access to this mountainous region.

\section{AFTERSHOCKS (GEOLOGICAL AND PSYCHOLOGICAL)}

From August 17 to December 14, 1999, a total of 1,391 aftershocks measuring between 2.4 and 5.2 RS were recordedan average of 12 per day. Initial assessments completed in the earthquake provinces showed that those who were psychologically affected included not only many families with young children and elderly grandparents, but also local police, firemen, soldiers, and municipal workers. Many relatives and friends were missing, and supply lines for basic services and goods were impaired or destroyed. Acute

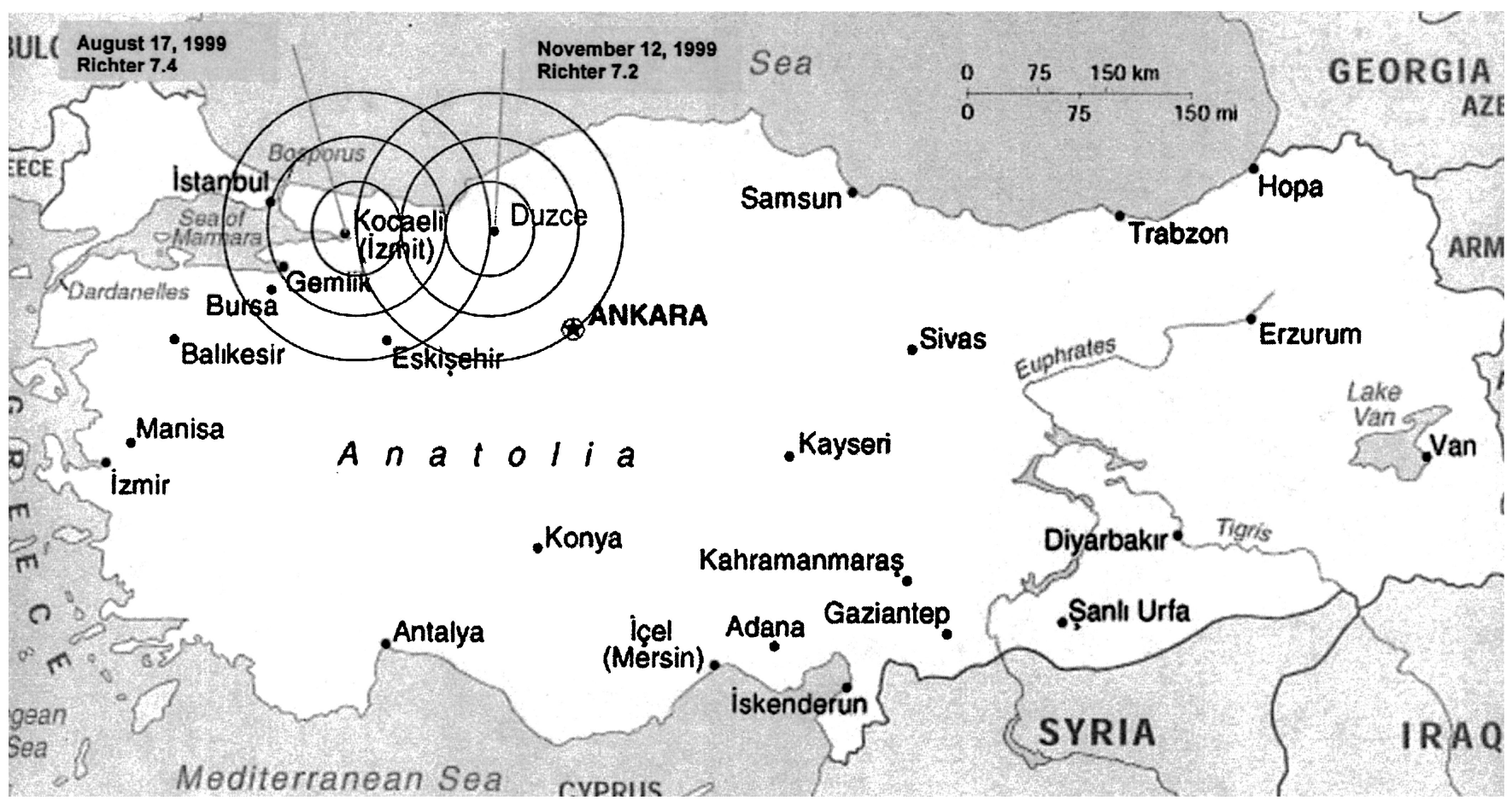

FIGURE 1. Map of Turkey: August 17 Marmara and November 12 Düzce Earthquake Epicenters. 
stress reactions were common, and the need for urgent aid was paramount. By January 2000 some 150,000 people were still accommodated in tents, with prefabricated settlements (which came to be referred to as "cities") being established continually. The reestablished education and health services were functioning under severe constraints. The Recovery Plan for Turkish Children under the UNICEF earthquake emergency program had estimated that more than $25 \%$ of the teachers in the region had been effectively incapacitated-either because they had been victims of the earthquakes themselves or because they returned to their homes in other parts of the country. ${ }^{7}$

\section{EARTHQUAKE INTENSITY}

A major earthquake of 7.0-7.9 RS can produce seismic waves up to 60 miles from the epicenter. The overall devastation caused by the two earthquakes was due to a triad of factors-intrinsic (tremor magnitude), local (proximity to epicenters, path of seismic waves, soil saturation), and social (poor construction, inadequate emergency-preparedness measures and public health policies, high population density, and time of occurrence [i.e., during the hours of sleep in the case of the Marmara earthquake]). These factors were especially significant during the Marmara earthquake even though the associated physical damage was mainly attributable not to the initial tremor but to a secondary effect-the sudden propagation of energy from a rupture of the North Anatolian Fault.

In terms of TNT equivalent, each earthquake produced an impact around 160 million tons. By comparison, a small, tactical nuclear weapon explosion, the equivalent of $4.0 \mathrm{RS}$, yields an equivalent of 1,000 tons TNT. The impact the two earthquakes could be seen over an area of 30,000 square kilometers. Over 290,000 buildings were destroyed. In İstanbul, with a population of 12 million at the time of the earthquake-and where millions had migrated during the previous decade-nearly $70 \%$ of the buildings constructed since 1980 had been put up without oversight. According to a nonquantitative, ordinal measure of felt effects of earthquake intensity, ${ }^{10}$ the tremors (at the epicenter) were ranked XI on the I-XII Mercalli scale (see text box). Some structures had rotated from their foundations. Others sank two stories into the ground. Many less stable or poorly constructed multistory apartment buildings "pancaked" onto themselves or just became rubble.

\section{SEISMIC DIPLOMACY}

Even though Turkey is one of the most earthquake-prone countries in Europe, the densely populated Istanbul region has remained relatively unscathed. The proximity of these
Abridged Modified Mercalli Scale of Earthquake Intensity

I. No one feels any movement

II. Few at rest or on upper floors of tall building feel movement

III. Many indoors feel movement; hanging objects sway

IV. Most indoors feel movement (as if a heavy truck had struck a wall)

V. Almost everyone feels movement; sleeping awakened; dishes break; pictures move

VI. Everyone feels movement; there is trouble walking, movement of furniture; pictures fall off walls (usually no structural building damage)

VII. Difficulty standing; damage slight in well-built and considerable in poorly built structures

VIII. Drivers cannot steer cars; unbolted houses move off foundations; water levels change; hillsides crack

IX. Well-built buildings suffer significant damage; houses bolted move off foundations; some underground pipes break; ground cracks; reservoirs sustain serious damage

X. Most buildings and their foundations are destroyed; some bridges destroyed; dams seriously damaged; large landslides; ground cracks in large areas; rail tracks slightly bent

XI. Most buildings collapse; large cracks on the ground; underground pipes destroyed; rail tracks badly bent

XII. Almost everything destroyed; ground moves in waves or ripples; large amounts of rock move

Adapted from Bolt BA. Abridged Modified Mercalli Intensity Scale. In: Earthquakes. Newly rev. \& expanded ed. New York: W.H. Freeman, 1993:331.

two recent earthquakes to İstanbul, however, elevated public awareness of earthquakes and the city's vulnerability. The tremors were also felt in Ankara, the capital, 300 miles west. Overwhelmed by the scale of the disaster, the government rapidly declared a national emergency and asked for international assistance. The Turkish Red Crescent Society, among the first to act by distributing tents and food and providing first aid, was joined by the International Federation of Red Cross and Red Crescent Societies, which sent search-and-rescue teams, food, blankets, tents, and medical aid. ${ }^{11}$

Among the first international teams on the scene of the Marmara earthquake was the Israeli National Rescue Unit. At 1:30 a.m. on the day after the earthquake, its airplanes landed at the international airport in İstanbul, reaching the epicenter at Gölcük within hours. The rescue effort of the Israeli field hospital was described as a "miracle of birth."12 A record number of countries and NGOs initiated outreach programs on an unprecedented scale for a natural disaster. The UNICEF mission (see next section) was especially important. The outreach efforts by neighboring Greece signified a new era of cooperation-a humanitarian gesture that 
led to "seismic diplomacy" and to a thawing of tensions that continues to the present. The newfound spirit of cooperation between the two countries culminated in a visit to Ankara by the Greek foreign minister-the first such visit in over 30 years.

\section{UNICEF-ASSOCIATED ACTIVITIES}

\section{Child-Friendly Environments}

The UNICEF mission, active in Turkey since 1951, has evolved from distributing milk in schools, to its present focus on child development, survival, protection, and human rights. In the immediate postdisaster period, the Recovery Plan for Turkish Children was established, under the earthquake emergency activities, to ensure that children would return quickly to a normalized environment. The childfriendly environments initiative has been responding-in Turkey and elsewhere - to the needs of children and mothers in postdisaster situations by providing early child care; primary school education; recreational activities; basic health and pediatric care, including nutrition; hygiene, water, and sanitation; youth activities; and parental and psychosocial support. The "safe havens" created through this initiative have allowed children to continue their schooling cycle without interruption, and have also given parents a respite from child care, allowing them to continue their own activities while the children remain within a safe, "holding" environment. ${ }^{13}$ This initiative also enabled mothers to spend quality time with their infants while receiving counseling and participating in support groups, through which they received information on topics ranging from healthy child development to reproductive health. ${ }^{14}$ A child who had experienced the enriched postdisaster atmosphere in the settlements is reported as having said, "I wish there would be another earthquake." 2

Despite the UNICEF intervention to establish childfriendly environments, children often continued to live in distressing circumstances. A disproportionate number of poor families with young children-mostly families of survivors of the earthquakes, but also some families of internally displaced migrants in the region prior to the earthquakes-sought government shelter and subsidies available to them in tent or prefabricated settlements. Especially in the immediate aftermath of the earthquakes, children and families were forced to live in overcrowded housing units, without play space and toys, but with a surplus of free time, in an atmosphere of mounting stress. These prefabricated units are still being used in once-prosperous towns such as Gölcük, which suffered a significant downturn in the postquake economic recession. Elsewhere, the units are now predominantly inhabited by homeless families that the municipality in question has certified as being in need of shelter, irrespective of earthquake exposure. During a recent follow-up visit with the people in the shelters by two of the authors, a young single mother noted sharply, "I would move out without a blink [of an eye (a common Turkish expression)] if I could, ... but I have to care for my innocent [child]." She continued to reside at the shelter with her parents - all displaced by the first earthquake-because they could watch her child while she tried to earn some money. The child-friendly environments no longer exist in the prefabricated settlements; many NGOs have moved on to other priority missions.

\section{Health, Nutrition, and Social Services}

In the wake of the earthquakes, many NGOs, including UNICEF, stepped in to provide relief, maintain public health, and to shore up and improve the services provided by primary health care centers, many of which were physically destroyed or damaged by the earthquakes. The organization's activities included an extensive effort to provide clean water, sanitary facilities, immunization, and nutritional fortification. UNICEF also provided basic medical supplies and refresher training in the management of infections and in maternal and child health care. ${ }^{15}$ This kind of support from UNICEF enabled primary health care personnel, with the support of MoH, to provide round-the-clock services (via rotating shifts). The organization also promoted a variety of awareness-raising activities such as those designed to reduce the stigma associated with mental disorders, which could lead to social exclusion. UNICEF also acted in tandem with Turkey's Department of Social Service and its Child Protection Administration to train social workers and other field workers to provide psychosocial support, as well as recreational activities, for children and their mothers. In addition to the activities of child-friendly environments as discussed above, day care centers ("crèches") and youth centers were established in tent camps. Such centers, which were in place only during the early recovery phase, have not otherwise been common in Turkey.

\section{Educational Kits-“Schools in a Bag”}

UNICEF acted in collaboration with the Ministry of National Education (MoNE) to support, supply, and generally reestablish schools in the areas affected by the earthquakes. Flooring pallets were used to provide the physical foundations for tent schools, which were then supplied with white boards, desks, and benches. The families of homeless teachers were provided with some form of essential housing. Immediately after the first earthquake, standard educational kits- "schools in a bag"-were airlifted in duffel bags or boxes. ${ }^{7}$ The kits could equip a class of 40 elementary school children with basic educational materials. Sometimes on a 
voluntary basis, and sometimes subject to a nominal payment, local manufacturers supplied the materials needed for the basic educational kits for primary schools, and for the recreational kits for preschools-enough for 50,000 children altogether. Since special-needs services were not part of mainstream public education in Turkey, 25 educational centers were supplied with "special needs kits" to help that group of students and to facilitate the development of cognitive and motor skills. These kits included construction paper and paints, building blocks, play dough, sand bags, balance boards, swing sets, ball pits, and trampolines.

\section{Psychosocial School Project}

At the time of the first earthquake, the schools had been closed for the summer break, and they remained so for another two months. Soon after the earthquake, counseling and psychosocial support services in the tent and prefabricated settlements were already under way, initiated by NGOs and led by the Turkish Psychological Association. ${ }^{16}$ Booklets, brochures, and flyers were developed to supplement the field psychoeducation and counseling efforts intended to reduce survivors' helplessness, anxiety, and guilt feelings related to trauma, and to prevent the development of persistent posttraumatic stress reactions.

The Psychosocial School Project was sponsored by MoNE and UNICEF, with the collaboration of international partners from the Center for Crisis Psychology (Bergen, Norway) and the Trauma Center (Allston, Massachusetts). ${ }^{17,18}$ UNICEF provided support for the training activities and materials, and also for the national expert team for this project. MoNE was responsible for the overall implementation.

This project included four complementary activities. The initial phase included the debriefing of teachers-many of whom had themselves had traumatic experiences and needed assistance-before the reopening of the schools. Many teachers found the sessions invaluable. One participant in these sessions reported, "I was afraid that I might make the children's problems worse given my state of mind. But gradually I found my self-confidence again, learning not to be afraid of the problems that came my way."17 Another teacher was quoted as saying, "I guess I had difficulty freeing the child inside me, but I learned how to do that soon enough. I saw I could solve problems with love." The second phase of activities included the classroom-based (psychosocial) interventions (CBIs) developed by Macy and colleagues. ${ }^{19,20}$ The CBIs were implemented by trained school counselors using creative and expressive-behavioral group therapy methods to help the children cope with aftereffects of the disaster. The activities included psychoeducation, movement and dance, art or "silent stories," drama, and cooperative games. The third phase involved provision of additional counseling and support services for moderate to severely traumatized children identified through the CBIs. These children included ones with various physical, emotional, cognitive-regulatory, and psychological problems. Finally, an expanded outreach program of psychoeducational activities was implemented in classrooms in order to reach a broader group of children, teachers, and parents than could be included in the original CBI program. ${ }^{17,18}$

For many surviving children their physical and psychological worlds had been literally turned upside-down, as homes and neighborhoods became tombs in which many perished. ${ }^{17}$ A 13-year-old boy who participated in the Psychosocial School Project reflected:

We were sleeping when the earthquake struck, and as soon as we felt the tremors, we ran from the house. My father went to help the neighbors, and I went with him. As I watched him trying to help a man from under the rubble, I thought I heard a deep voice crying for help from under some rubble nearby. I was shocked and stunned. I couldn't speak. I wasn't able to tell others that I had heard a voice beneath the rubble. After that I couldn't get over the feeling of guilt. I kept thinking that I might have saved that man.

A 12-year-old girl noted:

I had been very happy before the earthquake. Then I lost my brother, sister, aunt, uncle, grandmother, and cousins when it happened. I felt that my life was over. Then you came and showed me to love life all over again.

To our knowledge, the Psychosocial School Project was one of the largest school-based psychosocial-intervention programs ever undertaken following a natural disaster. From September 1999 to June 2001, the project debriefed and trained 289 school counselors and 8,235 teachers, and it reached 178,424 school-age children (of whom, 55,000 completed the CBI program). ${ }^{17,18}$ MoNE appointed the project team; the national expert team for this project worked collaboratively with the UNICEF field staff; and UNICEF mobilized international resource consultants and trauma experts to help with program development.

\section{Guidance and Research Centers}

Administered by the General Directorate of Special Education and Counseling Services (a division of MoNE), the Guidance and Research Centers traditionally served an important function in each province through the screening of children with serious developmental and intellectual disabilities. Strengthening these centers in each of the five earthquake provinces was one of the emergency-response goals of UNICEF. 
After the earthquake, MoNE passed new regulations, "Guidance and Counseling Services in Emergency Situations," which laid the foundation for incorporating mental health services into the educational system. Because of the expanded counseling services for children following the earthquakes, the staffing of the centers was increased; more training was provided; and additional resources were also made available. Working with a network of public schools, centers could serve as provincial resource units and provide appropriate triage and referral for specialty services, which were necessarily extensive in view of the large school-age population (31.7\% under 15 years of age) in the earthquake areas. A high prevalence of psychiatric comorbidity in school children was likewise described after the 1988 earthquake in Armenia. ${ }^{21}$ Since the capacity of the Psychosocial School Project was itself inadequate to meet the counseling needs of the children involved, the focus was predominantly on counselor training and supervision. With the earthquakes having affected such a large number of school-age children, the role of school counselors in the delivery of mental health services became more visible, especially with regard to crisis intervention in the schools.

\section{Community Mental Health Services}

Studies in developing countries have shown that at times of disaster, community mental health services tend to be either nonexistent or sparse and disorganized. ${ }^{22}$ Thus, in Turkey, the postdisaster period was characterized by voluntary and often uncoordinated mobile units or traveling teams of professionals who worked in collaboration with national and international NGOs, representatives of professional guilds, and university departments. They provided a range of interventions: debriefing, short-term crisis intervention, individual and group counseling, psychoeducation, cognitive-behavioral therapy, psychopharmacology, and even eye movement desensitization and reprocessing therapy. ${ }^{23}$ An initial focus of UNICEF (as it was with Turkey's own NGOs and with volunteers) was the alleviation of acute grief and posttraumatic reactions; other associated forms of anxiety; co-occurring depression; sleep and eating disorders; and psychological symptoms secondary to physical morbidity and disability. ${ }^{24-29}$

An assessment survey by the UNICEF psychosocial team six months after the Marmara earthquake indicated that more than half of the patients visiting primary health care centers presented primarily with psychological and somatic complaints. ${ }^{7}$ The survey not only confirmed the void in basic mental health services, but also underscored the ethical problem that even when such symptomatic patients were identified, there was no possibility of coordinated secondaryprevention interventions in the community. There was an urgent need for the development of a referral system and a formal mental health network in the earthquake provinces. A proposal submitted by the UNICEF psychosocial team (specifically, by KM) to the MoH's Directorate of Primary Health Care included a psychosocial-intervention program (parallel to the Psychosocial School Project) focused on revitalizing community mental health services through the training and support of practitioners, nurses, and midwives, and also on screening individuals who were at highest risk for developing disaster-related psychiatric problems. $^{30,31}$

A second set of recommendations to the same directorate proposed that issues of triage, referral, and treatment in the community be addressed through the creation of mental health service units in the provincial $\mathrm{MoH}$ general medical hospitals. Turkey has a unique situation in that more than half of its psychiatric specialists are trained in the Bakırköy State Psychiatric Hospital in Istanbul under the auspices of the MoH. The proximity of Bakırköy to the earthquake provinces and its affiliation with $\mathrm{MoH}$ made it an ideal choice for the coordination of $\mathrm{MoH}$ efforts in the nearby earthquake provinces. One recommendation involved the placement of graduates of the Bakırköy program in revitalized mental health units in the provincial $\mathrm{MoH}$ general medical hospitals, with those units being integrated, in turn, into the general health services. These newly appointed Bakırköy graduates, as staff psychiatrists, would provide, and help to coordinate, secondary-prevention and consultation services for the management of those patients who were comparatively seriously affected by the earthquake emergency. Especially at the peak of the emergency, this approach seemed to be the fastest way to draw young psychiatrists into the earthquake provinces and away from the metropolitan areas. A further recommendation was for Bakırköy psychiatry residents to do apprenticeships in "disaster and community psychiatry" by rotating through the provincial hospitals-analogous to the use of mental health rotations through "satellite" neighborhood health centers offering mental health services as a complement to, and as an integral part of, their general medical services. It was also hoped that the rotations by the psychiatry residents would have synergistic effects by improving the professional environment of staff psychiatrists working in the provinces and by developing the critical mass of psychiatric personnel that would be needed in order to establish an institute for disaster and community psychiatry. A final recommendation was that the MoH sponsor the establishment of just such an institute at Bakırköy; it was hoped that the institute would not only send an ongoing stream of trainees into the earthquake providence, but also become a national resource for disaster preparedness and emergency response.

The model for the proposed system of integrated general medical and mental health services and training is 
the one developed by the Massachusetts General Hospital (MGH), beginning in the $1960 \mathrm{~s}$, for its neighborhood health centers. ${ }^{32}$ (In this context, it is worth noting that in addition to having a worldwide reputation as a tertiary care facility, MGH has developed a unique approach to primary care and its interconnection with psychiatry-a role that emerged and then began to evolve in the wake of the hospital's postdisaster response to the tragic 1942 fire in Boston's Coconut Grove nightclub, which claimed 492 lives.) In addition to providing opportunities for young psychiatrists in community-based psychiatry, the integration of services at MGH's neighborhood health centers-which were perceived by the public simply as local institutions for the provision of primary medical care-allowed prospective patients suffering from depression, anxiety, somatic disorders, and so on to have those problems addressed by therapists (be they professional or paraprofessional) while not being stigmatized, in their own view or that of others, for suffering from, or being treated for, psychiatric problems.

There are many potential advantages to implementing in Turkey what might be called this "indigenous" therapeutic approach to providing mental health services. ${ }^{32}$ Working and living in the same neighborhoods as their patients would enable staff psychiatrists, psychiatric trainees, and other therapists to gain enhanced knowledge of their culture and values, which would foster, in turn, the formation of the therapeutic alliance, increase longitudinal knowledge of patients, and ultimately increase the effectiveness of therapeutic interventions. In our view, this approach's integration of general medical and mental health services is especially valuable in developing countries, where stigmatization and prejudices concerning mental disorders are rampant and present major barriers to obtaining care for such problems. It is also reasonable to assume that if such an approach could be implemented in Turkey, it would have a centrally formative impact on psychiatric trainees and young psychiatrists; it would shape their professional identities, sensitize them to the needs of traumatized populations, and provide them with vitally important experience in community and disaster psychiatry.

Unfortunately, the funding and implementation of such a multifaceted training program required the cooperation of another directorate of $\mathrm{MoH}$ (not just the Directorate of Primary Health Care), and there was insufficient political will to get the program approved. This situation can be contrasted with the commitment of MoNE to the Psychosocial School Project. Without that commitment, many more people needing mental health care would have received none, and many others would have received it only by traveling long distances to the psychiatric centers in the country's major cities.

\section{THE MARMARA EARTHQUAKE EMERGENCY RECONSTRUCTION (MEER) PROJECT'S MENTAL HEALTH ACTIVITIES: DEVELOPMENT OF A NATIONAL MENTAL HEALTH POLICY}

As the World Bank recognized when it approved the Marmara Earthquake Emergency Reconstruction (MEER) Project (with 1\% of the loan earmarked for mental health services), there was no coherent system of mental health services in the Marmara region despite that region's relative prosperity and level of economic development. ${ }^{33}$ The mental health component of the MEER Project identified the need to develop community-based mental health services-including trauma-related interventions related to the earthquakes-initially in the northwest where the earthquakes occurred, and later across the remainder of Turkey, thereby ensuring that the country would be better prepared for similar disasters. The plan was to establish (within each province) community mental health centers staffed by "a broad base of mental health professionals" who were trained in specialized mental health care for trauma victims and who were also able to provide long-term mental health services for more chronic conditions. The MEER Project's list of activities included a campaign for raising public awareness of mental health issues in relation to similar natural disasters that almost certainly will occur again in the future. The project also included a plan to establish a program that would provide psychological and organizational support to businesses affected by the earthquake.

The General Directorate of Primary Health Care accepted many of these suggestions as major objectives in its effort to improve community-based mental health services, ${ }^{34}$ thus marking the beginning of a new era in which $\mathrm{MoH}$ would push more aggressively for the development of a national mental health policy. An interdisciplinary team from the International Mental Health and Developmental Disabilities Program at the Children's Hospital (Boston) and Harvard Medical School, in collaboration with colleagues at Hacettepe and Ankara Universities, was commissioned to develop such a policy. The project entailed organizing three national conferences in Ankara involving a national team of experts, all nominated by the MEER Project team in the $\mathrm{MoH}$. Before even the first of those conferences was convened, however, the MEER Project team announced that a national program of training in mental health skills would be undertaken for practitioners, nurses, and midwives in over 5,000 primary care centers covering 11,000 health care positions. This mental health training program has yet to be undertaken, however, and though that program remains independent of the MoH's efforts to develop a national mental health policy, MoH's ambitious initial plans were cut back to include only the original earthquake catchment area. 
From the time that the first national mental health policy conference was held in Ankara in December 2002, it was evident that the policy project needed to be more inclusive, with inputs from a much wider variety of mental health professionals and allied sectors. The MoH national team comprised psychiatrists, child psychiatrists, and psychologists from leading departments in Ankara and İstanbul, as well as leading psychiatrists from the MoH-affiliated psychiatric specialty hospitals across Turkey. Understandably, a healthy level of skepticism was expressed as to the people and constituencies thereby excluded from the process of reform. It was also ironic that the Turkish public-with the exception of those in major metropolitan areas-had little representation even though the effort to develop a national mental health policy was motivated specifically by the government's desire to provide equitable mental health care throughout the provinces. In an effort to address these concerns, the International Mental Health and Developmental Disabilities Program has attempted to significantly broaden participation in the consultation and policymaking process.

During the second national mental health policy conference, which was held in Ankara the following March, the same major themes were discussed: child, adolescent, and adult services, and how to organize and finance them. Other issues included patients' rights, ${ }^{35}$ the need for mental health legislation (currently nonexistent), and the promotion of interagency cooperation. ${ }^{36,37}$ The increased interest in, and attention to, patients' rights and institutional and provider responsibilities was especially timely since there is currently-in connection with Turkey's proposed accession to the European Union-a climate of change pervading many sectors of Turkish society. By the same token, as Turkey moves toward becoming an increasingly urban, rather than rural, society-and with the associated shift from extended to nuclear families concentrated in metropolitan centers-an emphasis on social inclusion, coupled with policies promoting access to housing, social supports, domiciliary care, income security, employment, and work-training opportunities, will surely prove to benefit individuals suffering from mental disabilities. ${ }^{38,39}$ With respect to disaster preparedness, the need for collaboration among different state ministries and departments, the Institute of Statistics, universities, NGOs, consumer and business sectors, and the media has been highlighted. In particular, through such collaboration the differential needs of the provinces could be identified, and certain provinces could be designated as requiring urgent attention to disaster preparedness. ${ }^{40}$ An overarching objective has been to strengthen local and regional systems for quickly responding to disasters, thereby mitigating the potential harm, especially with respect to vulnerable groups such as women and children. ${ }^{14}$
During both the first and second conferences, and in order to develop a fully representative national mental health policy, roundtable discussions were held, nationwide polling was conducted of $\mathrm{MoH}$-affiliated regional psychiatric specialty hospitals and provincial mental health departments, and various mental health and allied professional associations were invited to comment on, and submit formal position statements concerning, the national mental health policy. ${ }^{2,5,41,42}$ These statements-which have already been submitted by the associations for Turkish Psychiatry, Child and Adolescent Psychiatry, Psychology, Counseling and Guidance, Public Health, Nursing, Psychiatric Nursing, Social Service, and Child Protection-will be incorporated into the final policy document to be presented to the $\mathrm{MoH}$ prior to the third and final conference, to be held in the fall of 2004. Also to be included in that document are the results of consultations with the Department of Health Care Management at Başkent University in Ankara, which has had a leading role in the WHO World Health Survey of Turkey, as well as in the study of Turkey's national burden of disease and the cost-effectiveness of its essential health services.

There have been previous national mental health consensus meetings convened by the $\mathrm{MoH}$, and they date back many years. Some of the basic ideas being discussed in the current policy debate had been raised earlier. ${ }^{43-46}$ Those prior meetings had also emphasized, in particular, the importance of providing mental health services in primary care and the need to integrate such services within general health care. They had also prioritized the need for addressing regional inequities, as well as the need for appropriate allocation of resources for the treatment of chronically ill patients.

To date, the current national debate on mental health policy has been much broader, in terms of both duration and public exposure, than previous iterations. Even so, it is not clear that the current reform effort will succeed, even with the sponsorship of the General Directorate of Primary Health Care in the MoH. National workshops and symposia have generated considerable support for reform, and concerned interest groups have likewise voiced their support. Nevertheless, with so many competing priorities-and ultimately so many competing interest groups-sufficient impetus for reform may not be forthcoming.

Of central concern for Turkish public psychiatry remains the plight of the five regional psychiatric specialty hospitals (in İstanbul [Bakırköy Hospital], Adana, Elazığ, Manisa, and Samsun) that are administered not under MoH's General Directorate of Primary Health Care, but under its General Directorate of Curative Services. These hospitals continue to be populated predominantly by chronically ill patients from economically poor backgrounds, who have long lengths of stay and inadequate social supports in their home communities. The barriers associated with the discharge of such patients have been further complicated by the 
distribution of psychiatrists in Turkey. Since the large majority of public sector psychiatrists are concentrated in the five regional psychiatry hospitals or provincial general hospitals in large cities, the distribution of psychiatrists in the remote provinces continues to be especially sparse; for example, a single psychiatrist is responsible for eight or more eastern Anatolian cities. ${ }^{47}$ The five regional psychiatric specialty hospitals continue to serve vast catchment areas with very limited resources allocated to community-based outreach rehabilitation and social services. ${ }^{43,44}$ Although regulations have been put into effect regarding the referral and follow-up of patients, many patients would nevertheless return to the tertiary care setting in the absence of an organized network of care in the community. As a nationally recognized center, Bakırköy has continued to face challenges since many patients would chose to travel to İstanbul not only for tertiary care, but even for primary and secondary care. In order to address the overwhelming demand, Bakırköy has recently established an invigorated screening and triage requirement to assign an appropriate and urgent level of care for the highest risk patients and to develop alternative tiers of care with partnerships in the community (Tosun M [psychiatristin-chief, Bakırköy Psychiatric Specialty Hospital], personal communication, 2004).

\section{CONCLUSIONS}

Sudden and unexpected trauma and internal displacement associated with natural disasters progressively expose, over time, new layers of loss, and new sources of stress: experiencing and witnessing of multiple traumas; deprivation of safety and basic needs; and loss of family, possessions, and identity, only to list a few. ${ }^{48,49}$ The population of Turkey during the Marmara and Düzce earthquakes suffered from devastating loss of life, as well as from physical injuries, psychological trauma, displacement, and confinement in shelters. ${ }^{50,51}$ Furthermore, the earthquake disaster magnified the existing deficiencies in the mental health services across the provinces. National and international NGOs and professional associations played a key role in providing a patchwork of mental health services in the immediate aftermath of the disaster.

The Psychosocial School Project, launched by MoNE and UNICEF, provided crucial support for teachers and students in the post-earthquake recovery and facilitated the children's reentry into the schools. Despite much discussion, there has been no equivalent, parallel effort to bolster the mental health services in the earthquake provinces. It is open to question, however, whether-given the lack of an established system of mental health care-a single, concentrated effort to train primary care staff in mental health skills could make a significant difference in improving mental health services in the provinces, ${ }^{52,53}$ either in the short or long term. A much more organized and sustained effort is required.

Unfortunately, in the years since the earthquakes, funding limits and competing obligations have understandably led many NGOs, including UNICEF, to direct their efforts elsewhere. Some NGOs, however-for example, Project Hope-have both maintained support well into the postdisaster period and transferred developed services to local universities and foundations. Some have funded minifellowships to support the work of professionals conducting research in the disaster region. The International Mental Health and Developmental Disabilities Program at the Children's Hospital (Boston) and the Fogarty International Center have also provided ongoing support for such efforts in the postdisaster era.

In our view the mental health departments of the provincial health directorates across Turkey were seriously deficient for the purpose of responding effectively to the earthquake emergency, whereas their counterparts in pre- and postnatal maternal and child health and family planning were extremely successful in reducing infant and maternal mortality and morbidity rates. In this context, it is worth noting that the mental health positions in provincial directorates were typically occupied by persons who lacked expertise in mental health and were incapable of taking on a leadership role, and that many of these positions were actually vacant when the earthquakes struck.

A dynamic coordination of mental health services is needed in the provinces, and this effort must combine political will, vision, and familiarity with regional customs and cultural variation. ${ }^{54-59}$ But there is a long road ahead; for example, with the exception of two university-affiliated psychiatrists in Kocaeli, no psychiatric specialists lived and worked full-time in the earthquake provinces at the time the disaster occurred. The extraordinary work of this husbandand-wife team has demonstrated how vitally important it is to invest in people who would stay on, and build capacities within, the communities that they serve.

In the Marmara quake, the newly built medical center in Kocaeli was severely damaged, and it remains unoccupied to this day; many of the medical center's academic departments have been set up, instead, in prefabricated units. It is impossible to go anywhere in these communities without encountering reminders of the earthquake. Even so, Kocaeli and also Bolu, Düzce, Gölcük, Sakarya, and Yalova all represent excellent examples of community responsiveness. The fruits of these efforts include the recent establishment of a Psychological Trauma Center in Kocaeli-a partnership between academia, municipal government, and industry 
that is, in effect, an extension of the work begun, of necessity, during the earthquake emergency. It is encouraging that such "centers of excellence," once envisioned for Bakırköy alone, are starting to be seen on the local level.

Green ${ }^{60,61}$ has characterized events that cause a transforming change in the makeup of a community as central disasters. The Marmara and Düzce earthquakes have already transformed the earthquake provinces in many ways-physically, economically, and psychologically. But more importantly, they have transformed the nation, causing a major downturn in the economy and the devaluation of the lira, influencing foreign policy and the Armed Forces' role in, and responsiveness to, domestic emergencies, and so on. The earthquakes undoubtedly also changed the public's perception of mental health. Compared to the predisaster era, the stigma associated with mental illness is less; the relationship between the professions of psychiatry, child psychiatry, and psychology is more productively competitive and interactive; a higher value is beginning to be placed on social services and on the role of nurses and nurse midwives in the community; and there is a recognized need for much more extensive training and research in mental health. Compared to any previous experience of disaster, it is precisely because the earthquakes were so devastating and central that they have provided a window of opportunityand some promise-for a new, modern approach to mental health policy in Turkey.

The authors would like to thank Phillippe Heffinck, William Gardner, Mine Süngün, Ayşe Yalın, Nurper Ülküer, Yakut Temuroğlu, and Jane Barham (UNICEF, Turkey); Toril Araldsen, Per Ole Tomassen, and Rune Stuvland (Center for Crisis Psychology, Bergen, Norway); Robert Macy (Trauma Center, Allston, MA); Toker Ergüder, Tahir Soydal, and Cihanser Erel (General Directorate of Primary Health Care, Ministry of Health, Turkey); Mustafa Sercan, Sezai Berber, Berna Uluğ, and İsmet Kırpınar (Turkish Psychiatric Association); Nail Şahin, Nesrin Şahin, and İhsan Dağ (Turkish Psychological Association); Füsun Çuhadaroğlu (Turkish Child Psychiatry Association); Gül Aydın (Turkish Counseling and Guidance Association); Bülent Coşkun, Aysen Coşkun, Tamer Aker, and Emin Önder (Kocaeli University); Musa Tosun (Bakırköy Psychiatric Specialty Hospital, İstanbul); Mustafa Namlı (Elaziğ Psychiatric Specialty Hospital); Oğuz Karamustafaoğlu (Şisli Etfal Hospital, İstanbul); Adnan Kısa and Şahin Kavuncubaşi (Başkent University); İskender Sayek, Ahmet Göğüş, Nazmi Bilir, Serhat Ünal, and Aykut Toros (Hacettepe University); Abdulkadir Çevik, Efser Kerimoğlu, and Işık Sayıl (Ankara University); Cengiz Kılıç (Abant İzzet Baysal University); Orhan Öztürk (Turkish Journal of Psychiatry); Angela Hassiotis (University College London); Beat Mohler (University of Zurich); Joseph Marrone and William Kiernan (Institute for Community Inclusion, Boston); Peter Berman Seedang Simonin, and James Ware (Harvard School of Public Health); Alex Cohen, Gordon Harper, Myron Belfer, Leon Eisenberg, William Beardslee, Judy Palfrey, and Julius Richmond (Harvard Medical School).

\section{REFERENCES}

1. Cifter I. Turkey. In: Kemp DR, ed. International handbook of mental health policy. Westport, CT: Greenwood Press, 1993:367-89.

2. Sercan M, Berber S, Ulug B, Kirpinar I. Views of the Turkish Psychiatry Association: we should have a sustainable psychiatry policy. In: Munir K, ed. National mental health policy for Turkey [in Turkish and English]. Ankara: Ministry of Health [Turkey], 2004.

3. World Health Organization. Project Atlas. Country Profile: Turkey. At http://www.cvdinfobase.ca/mh-atlas/database.htm.

4. Eist HI. Psychiatric workforce: there aren't enough psychiatrists. Psychiatr News 2004 (July 9). At http://www.psych. org.

5. Cuhadaroglu F. The framework for mental health policy for children and adolescents. In: Munir K, ed. National mental health policy for Turkey [in Turkish and English]. Ankara: Ministry of Health [Turkey], 2004.

6. Kilic C, Rezaki M, Ustun TB, Gater RA. Pathways to psychiatric care in Ankara. Soc Psychiatry Psychiatr Epidemiol 1994;29:131-6.

7. UNICEF. Recovery plan for Turkish children: situation report (21 February 2000). Ankara: UNICEF, 2000.

8. Goenjian AK, Najarian LM, Pynoos RS, et al. Posttraumatic stress reactions after single and double trauma. Acta Psychiatr Scand 1994;90:214-21.

9. Yehuda R, Kahana B, Schmeidler J, et al. Impact of cumulative lifetime trauma and recent stress on current posttraumatic stress disorder symptoms in Holocaust survivors. Am J Psychiatry $1995 ; 152: 1815-8$.

10. Bolt, BA. Abridged Modified Mercalli Intensity Scale. In: Earthquakes. Newly Rev. \& expanded. New York: W.H. Freeman, 1993: appendix.

11. International Federation of Red Cross and Red Crescent Societies. World disasters report 1996. Oxford: Oxford University Press, 1996.

12. Ashkenazi I. The disaster in Turkey-a personal account. Israel Med Assoc J 1999;1:73-4.

13. Winnicott DW. The maturational processes and the facilitating environment: studies in the theory of emotional development. New York: International Universities Press, 1965.

14. Gardner W. UNICEF activities following the August 17 and November 12 Turkish earthquakes: disaster and emergency preparedness and management. Paper presented at the 13th Commemorative Mualla Ozturk Child Psychiatry Conference, Ankara University School of Medicine, Ankara, Turkey, February, 2000.

15. Bracken P, Thomas P. Postpsychiatry: a new direction for mental health. BMJ 2001;322:724-7.

16. Special earthquake edition. Turkish Psychol Bull 1999;5:1120.

17. UNICEF. Less fearful, more active: the Psychosocial Project for Children Affected by the 1999 Earthquake in Turkey. Ankara: UNICEF, 2001.

18. Ministry of National Education [Turkey]. The Ministry of National Education-UNICEF Psychosocial School Project. 
Assessment and evaluation. Ankara: Ministry of National Education [Turkey], 2001.

19. Macy RD, Macy DJ, Gross S, Brighton P. Basic and advanced training manual for the 12 -session classroom based psychosocial intervention program (CBI): stress inoculation targeting threat \& terror for K-8th grade youth. Version 1.2. Brookline, MA: Arbour Health Systems-Center for Trauma Psychology, 2003.

20. Macy RD, Macy DJ, Gross SI, Brighton P. Healing in familiar settings: support for children and youth in the classroom and community. In: Macy RD, Barry S, Noam GG, eds. Youth facing threat and terror: supporting preparedness and resilience. San Francisco: Jossey-Bass, 2003:51-79.

21. Goenjian AK, Pynoos RS, Steinberg AM, et al. Psychiatric comorbidity in children after the 1988 earthquake in Armenia. J Am Acad Child Adolesc Psychiatry 1995;34:1174-84.

22. Cohen, Raquel E. Mental health services in disasters: instructor's guide. Washington, DC: Pan American Health Organization, 2000.

23. Shapiro F. Eye movement desensitization and reprocessing: basic principles, protocols, and procedures. New York: Guilford, 1995.

24. Yehuda R, McFarlane AC, Shalev AY. Predicting the development of posttraumatic stress disorder from the acute response to a traumatic event. Biol Psychiatry 1998;44:1305-13.

25. Cuhadaroglu F, Yazici KM. Psychiatric symptoms among Turkish adolescents. Turk J Pediatr 1999;41:307-13.

26. Basoglu M, Salcioglu E, Livanou M. Traumatic stress responses in earthquake survivors in Turkey. J Trauma Stress. 2002;15:269-76.

27. Livanou M, Basoglu M, Marks IM, et al. Beliefs, sense of control and treatment outcome in post-traumatic stress disorder. Psychol Med 2002;32:157-65.

28. Livanou M, Basoglu M, Salcioglu E, Kalendar D. Traumatic stress responses in treatment-seeking earthquake survivors in Turkey. J Nerv Ment Dis 2002;190:816-23.

29. Salcioglu E, Basoglu M, Livanou M. Long-term psychological outcome for non-treatment-seeking earthquake survivors in Turkey. J Nerv Ment Dis 2003;191:154-60.

30. Lima BR, Pai S, Santacruz H, Lozano J, Luna J. Screening for the psychological consequences of a major disaster in a developing country: Armero, Colombia. Acta Psychiatr Scand 1987;76:561-7.

31. Lima BR, Chavez H, Samaniego N, et al. Disaster severity and emotional disturbance: implications for primary mental health care in developing countries. Acta Psychiatr Scand 1989;79:7482.

32. Borus JF, Anastasi M, Casoni R, et al. Psychotherapy in the goldfish bowl: the role of the indigenous therapist. Arch Gen Psychiatry 1979;36:187-90.

33. World Bank. Project appraisal document on a proposed loan to the Republic of Turkey for a Marmara Earthquake Emergency Reconstruction Project. Europe and Central Asia Regions. Washington, DC: World Bank, 1999 [Report No. 19844-TU].

34. General Directorate of Primary Health Care, Ministry of Health [Turkey]. Primary health care approach to psychosocial trauma. Ankara: Ministry of Health [Turkey], 1999.
35. Tengilimoglu D, Kisa A, Dziegielewski SF. What patients know about their rights in Turkey. J Health Soc Policy 2000;12:5369.

36. Whiteford HA. Australia's National mental health policy. Hosp Community Psychiatry 1993;44:963-6.

37. Jenkins R, McCullogh A, Friedli L, Parker C. Developing a national mental health policy. London: Psychology Press, 2002.

38. Perkins RE, Repper J. Principles of working with people who experience serious mental health problems. In: Brooker C, Repper J, eds. Serious mental health problems in the community: policy, practice and research. London: Balliere Tyndal, 1999:16-35.

39. Kisioglu A, Uskun E, Ozturk M. Socio-demographical examinations on disability prevalence and rehabilitation status in southwest of Turkey. Disabil Rehabil 2003;25:1381-5.

40. Ulusoy M. Clustering of provinces according to socio-economic variables. Nufusbil Dergisi [Turkish Journal of Population Studies] 1993;15:69-78.

41. Ulug B. (2003) National Mental Health Policy Conference convened in Ankara [in Turkish]. Bull Psychiatr Assoc Turkey 2003;3:6.

42. Coskun B. Psychiatry in Turkey: country profile. Bull Int Board $\mathrm{R}$ Coll Psychiatrists (in press).

43. Coskun B. Resources, difficulties and solutions regarding mental health services in Turkey [in Turkish]. Toplum ve Hekim 1987;44:11-5.

44. Coskun B. Activities of the Department of Mental Health [in Turkish]. Mental Health Bulletin [Turkey] 1988;1:7.

45. Bayülkem F. Historical development of neurology, neurosurgery and psychiatry in Turkey [in Turkish]. İstanbul: Arbas, 1998:155-65.

46. Dag I. The systematic studies on national mental health policy in Turkey [in Turkish]. Psikiyatri Psikoloji Psikofarmakoloji Dergisi 2003;11:59-67.

47. Sercan M. Panel presentation on the views of the Turkish Psychiatry Association. In: Proceedings of the Second National Mental Health Policy Conference, March 12, 2003 [in Turkish]. Ankara: Ministry of Health [Turkey], 2003.

48. Lima BR, Pai S, Toledo V, et al. Emotional distress in disaster victims. A follow-up study. J Nerv Ment Dis 1993;181:38893.

49. Bar-Dayan Y, Beard P, Mankuta D, et al. An earthquake disaster in Turkey: an overview of the experience of the Israeli Defence Forces (IDF) Field Hospital in Adapazarı. Disasters 2000;24:262-70.

50. Laor N, Wolmer L, Kora M, et al. Posttraumatic, dissociative and grief symptoms in Turkish children exposed to the 1999 earthquakes. J Nerv Ment Dis 2002;190:824-32.

51. Kilic C, Ulusoy M. Psychological effects of the November 1999 earthquake in Turkey: an epidemiological study. Acta Psychiatr Scand 2003;108:232-8.

52. Isaac M, Janca A, Costa e Silva JA. A review of the World Health Organization's work on primary care psychiatry. Prim Care Psychiatry 1995;1:179-85.

53. Cohen A. The effectiveness of mental health services in primary care: view from the developing world. Geneva: World Health Organization, 2001. 
54. Cohen RE, Klerman GL, Ahearn FL. Handbook for mental health care of disaster victims. Baltimore, MD: Johns Hopkins University Press, 1980.

55. Kemp DR. An overview of mental health policy from an international perspective. In: International handbook of mental health policy. Westport, CT: Greenwood Press, 1993:1-18.

56. Ursano RJ, Fullerton CS, Norwood AE. Psychiatric dimensions of disaster: patient care, community consultation, and preventive medicine. Harv Rev Psychiatry 1995;3:196-209.

57. Saleh MA. Disasters and crises: challenges to mental health counseling in the twenty-first century. J Educ 1996;116(4).

58. World Health Organization. Earthquakes and people's health. Vulnerability reduction, preparedness, and rehabilitation. Pro- ceedings of a WHO symposium. Kobe: WHO Centre for Health Development, 1997 [Doc. WHO/WCK/SYM/96.1].

59. Flynn BW. Disaster mental health: the U.S. experience and beyond. In: Leaning J, Briggs SM, Chen LC, eds. Humanitarian crises: the medical and public health response. Cambridge: Harvard University Press, 1999:97-124.

60. Green BL: Assessing levels of psychological impairment following disaster: consideration of actual and methodological dimensions. J Nerv Ment Dis 1982;170:544-52.

61. Green BL, Solomon SD. The mental health impact of natural and technological disasters. In: Freedy JR, Hofoll SE, eds. Traumatic stress: from theory to practice. New York: Plenum Press, 1995. 